\title{
Effects of dietary fat and conjugated linoleic acid on plasma metabolite concentrations and metabolic responses to homeostatic signals in pigs
}

\author{
E. Ostrowska ${ }^{1}$, R. F. Cross ${ }^{2}$, M. Muralitharan ${ }^{3}$, D. E. Bauman ${ }^{4}$ and F. R. Dunshea ${ }^{1} *$ \\ ${ }^{1}$ Agriculture Victoria, Victorian Institute of Animal Science, Werribee, Victoria 3030, Australia \\ ${ }^{2}$ Swinburne University of Technology, Hawthorn, Victoria 3122, Australia \\ ${ }^{3}$ Deakin University, Geelong, Victoria, Australia \\ ${ }^{4}$ Cornell University, Ithaca, NY 14853, USA
}

(Received 19 November 2001 - Revised 10 June 2002 - Accepted 11 August 2002)

\begin{abstract}
Sixteen female cross-bred (Large White $\times$ Landrace) pigs (initial weight $65 \mathrm{~kg}$ ) with venous catheters were randomly allocated to four treatment groups in a $2 \times 2$ factorial design. The respective factors were dietary fat $(25$ or $100 \mathrm{~g} / \mathrm{kg}$ ) and dietary conjugated linoleic acid (CLA; 0 or $10 \mathrm{~g} \mathrm{CLA}-55 / \mathrm{kg}$ ). Pigs were fed every $3 \mathrm{~h}$ (close to ad libitum digestible energy intake) for $8 \mathrm{~d}$ and were bled frequently. Plasma glucose and non-esterified fatty acid (NEFA) responses to insulin and adrenaline challenges were determined on day 8. Plasma concentrations of NEFA were significantly increased (10.5 and $5.4 \%$ for low- and high-fat diets respectively, $P=0.015$ ) throughout the experiment, suggesting that there was a possible increase in fat mobilisation. The increase in lipolysis, an indicator of $B$-adrenergic stimulated lipolysis, was also evident in the NEFA response to adrenaline. However, the increase in plasma triacylglycerol (11.0 and $7.1 \%$ for low- and high-fat diets respectively, $P=0.008)$ indicated that CLA could have reduced fat accretion via decreased adipose tissue triacylglycerol synthesis from preformed fatty acids, possibly through reduced lipoprotein lipase activity. Plasma glucose, the primary substrate for de novo lipid synthesis, and plasma insulin levels were unaffected by dietary CLA suggesting that de novo lipid synthesis was largely unaffected $(P=0.24$ and $P=0.30$ respectively). In addition, the dietary CLA had no effect upon the ability of insulin to stimulate glucose removal.
\end{abstract}

Conjugated linoleic acids: Lipid metabolism: Pigs

The potential of conjugated linoleic acids (CLA) to reduce body fat deposition has been well documented (Albright et al. 1996; Park et al. 1997; West et al. 1998; DeLany et al. 1999; Ostrowska et al. 1999; Park et al. 1999a,b; Satory \& Smith, 1999), but whether the reduction in fat deposition is due to increased lipolysis (fat breakdown) or decreased lipogenesis (fat synthesis) is unclear. One way to understand the in vivo metabolic responses to CLA better is by studying the temporal pattern of intermediate metabolite and hormone concentrations. The effect of CLA treatment on lipolysis can be further investigated by determining the metabolic responses to homeostatic signals, such as adrenaline or insulin. Adrenaline stimulates $\beta$-adrenergic lipolysis (Sechen et al. 1990; Dunshea et al. 1995; Dunshea \& King, 1995), whereas insulin enhances storage of fat while inhibiting the mobilisation and oxidation of fatty acids in vivo (Dunshea et al. 1995; Dunshea \& King, 1995). Quantifying the plasma glucose response to insulin may also help to establish whether CLA induces insulin resistance, as this is characterised by high levels of plasma glucose and insulin (Dunshea \& King, 1994). These techniques have previously been used to determine the mode of action of metabolic modifiers such as somatotropin (Sechen et al. 1990; Boisclair et al. 1994) and ractopamine (Dunshea et al. 1995; Dunshea \& King, 1995).

The first objective of the present study was to determine the effect of the CLA treatment on plasma variables related to lipolysis and lipogenesis in growing pigs. The second objective was to measure the metabolic responses to the homeostatic signals, adrenaline and insulin.

\section{Experimental methods}

Animals and treatments

All procedures involving animals were approved by the 
Victorian Institute of Animal Science Animal Ethics Committee. Twenty female cross-bred (Large White $\times$ Landrace) gilts (initial weight $65 \mathrm{~kg}$ ) were catheterised $7 \mathrm{~d}$ before commencement of the study. Muscle relaxation was induced with an intramuscular injection of xylazine (20 mg xylazine.HCl/ml; Troy Labs Pty. Ltd, Smithfield, New South Wales, Australia) and ketamine (100 mg ketamine. $\mathrm{HCl} / \mathrm{ml}$; Troy Labs Pty. Ltd) at $0.05 \mathrm{ml}$ and $0.1 \mathrm{ml} /$ $\mathrm{kg}$ body weight respectively. The anaesthesia was maintained with halothane (Rhone Merieux, Footscray West, Victoria, Australia) inhalation. A silastic catheter was inserted $0.15 \mathrm{~m}$ into the anterior vena cava via the cephalic vein. The catheter was exteriorised in the region of interscapular space on the back of each animal and stored in a cloth pocket glued to the back. After catheterisation, pigs were given $10 \mathrm{mg}$ broad-spectrum antibiotic Engemycin 100 (100 mg oxytetracycline hydrochloride/ml; Intervet (Australia) Pty. Ltd, Castle Hill, New South Wales, Australia)/kg body weight. The twenty surgically prepared gilts were monitored for feeding behaviour, rectal temperature, general disposition and defecation frequency. Any pigs with elevated temperatures $\left(>39^{\circ} \mathrm{C}\right)$ were given $5 \mathrm{mg}$ Penbritin (ampicilin sodium; Beecham Veterinary Products, Dandenong, Victoria, Australia) $/ \mathrm{kg}$ body weight. Catheters were flushed daily with physiological saline containing $\mathrm{K}_{2}$ EDTA $(12.5 \mathrm{~g} / \mathrm{l})$. The sixteen gilts with the best functional catheters were blocked on live weight and within blocks randomly allocated to four treatment groups in a $2 \times 2$ factorial design. The respective factors were level of dietary CLA ( 0 and $10 \mathrm{~g} / \mathrm{kg}$ ) and total dietary fat $(25$ and $100 \mathrm{~g} / \mathrm{kg})$.

Four days before the initiation of the dietary treatments, all pigs were fed a diet containing no CLA and an intermediate fat level (about $60 \mathrm{~g} / \mathrm{kg})(75 \mathrm{~kJ}$ digestible energy/ $\mathrm{kg}$ live weight) every $3 \mathrm{~h}$ (about $2.5 \mathrm{~kg}$ feed $/ \mathrm{d}$ for a $60 \mathrm{~kg}$ pig or approximately $90 \%$ ad libitum digestible energy) to ensure a relatively steady state for measuring plasma metabolites. On day 1, pigs were offered their respective experimental diets at the same rate and frequency for $8 \mathrm{~d}$. Pigs were fed either a low-fat diet (total fat $25 \mathrm{~g} / \mathrm{kg}$; Table 1) or a high-fat diet (total fat $100 \mathrm{~g} / \mathrm{kg}$; Table 1) with either 0 or $10 \mathrm{~g}$ CLA-55 (CLA containing $55 \mathrm{~g}$ fatty acids as CLA isomers $/ 100 \mathrm{~g}$ total fatty acids; Natural Lipids Ltd, Hovdebygda, Norway)/kg. Pigs were fed for $8 \mathrm{~d}$, during which time they were bled frequently (see later). The added fat in the high-fat diet was provided as palm oil, thereby ensuring that saturated fatty acids were the predominant preformed fatty acids. The wheat-based diets were formulated to contain 14 and $15 \mathrm{MJ}$ digestible energy $/ \mathrm{kg}$ low- and high-fat diet respectively.

After commencing the dietary treatments, all pigs were bled $(8 \mathrm{ml}$ blood) at intervals of $3 \mathrm{~h}$ (immediately before each feeding) for $48 \mathrm{~h}$. From day 3 until day 7 pigs were bled twice per $\mathrm{d}$ immediately prior to feeding at 09.00 and 18.00 hours. Previous studies have demonstrated that plasma metabolites are in a steady state in pigs fed at intervals of 2 to 4 h (Dunshea et al. 1992a; Dunshea \& King, 1994) and it was felt that two samples taken $9 \mathrm{~h}$ apart would be representative of plasma metabolite concentrations in these pigs. A subsequent $24 \mathrm{~h}$ bleed took place on day 7 (at intervals of $3 \mathrm{~h}$ for $24 \mathrm{~h}$ ). Blood was collected
Table 1. Composition of the low- and high-fat diets

\begin{tabular}{|c|c|c|c|c|}
\hline \multirow[b]{2}{*}{ Ingredient (g/kg) } & \multicolumn{2}{|c|}{ Low-fat diet ${ }^{\star}$} & \multicolumn{2}{|c|}{ High fat diet† } \\
\hline & Control & CLA & Control & CLA \\
\hline Wheat & 189.4 & 189.4 & 484.8 & $484 \cdot 8$ \\
\hline Starch & $236 \cdot 0$ & $236 \cdot 0$ & 0.0 & 0.0 \\
\hline Raw sugar & $250 \cdot 0$ & $250 \cdot 0$ & 0.0 & 0.0 \\
\hline DL-Methionine & 2.5 & 2.5 & 0.6 & 0.6 \\
\hline L-Lysine $\mathrm{HCl}$ & $2 \cdot 5$ & 2.5 & 0.0 & 0.0 \\
\hline L-Threonine & $2 \cdot 3$ & $2 \cdot 3$ & 0.8 & 0.8 \\
\hline Dicalcium phosphate & $23 \cdot 3$ & $23 \cdot 3$ & 24.4 & 24.4 \\
\hline $\mathrm{NaCl}$ & $2 \cdot 0$ & $2 \cdot 0$ & $2 \cdot 0$ & $2 \cdot 0$ \\
\hline Limestone & 0.0 & $0 \cdot 0$ & $6 \cdot 9$ & $6 \cdot 9$ \\
\hline Vitamin and mineral premix $\ddagger$ & $2 \cdot 0$ & $2 \cdot 0$ & $2 \cdot 0$ & $2 \cdot 0$ \\
\hline Blood meal & $30 \cdot 0$ & $30 \cdot 0$ & 0.0 & 0.0 \\
\hline Fish meal & $50 \cdot 0$ & $50 \cdot 0$ & $50 \cdot 0$ & $50 \cdot 0$ \\
\hline Soyabean meal & $200 \cdot 0$ & $200 \cdot 0$ & $149 \cdot 0$ & $149 \cdot 0$ \\
\hline Palm oil & $10 \cdot 0$ & 0.0 & $80 \cdot 0$ & $70 \cdot 0$ \\
\hline CLA-55§ & 0.0 & $10 \cdot 0$ & 0.0 & $10 \cdot 0$ \\
\hline
\end{tabular}

CLA, conjugated linoleic acid.

*Diet was formulated to contain $14 \mathrm{MJ}$ digestible energy, $183 \mathrm{~g}$ crude protein $(\mathrm{N} \times 6.25)$ and $10.3 \mathrm{~g}$ available lysine $/ \mathrm{kg}$ air-dried diet.

†Diet was formulated to contain $15 \mathrm{MJ}$ digestible energy, $206 \mathrm{~g}$ crude protein $(\mathrm{N} \times 6.25)$ and $11.3 \mathrm{~g}$ available lysine $/ \mathrm{kg}$ air-dried diet.

$\ddagger$ Provided the following nutrients ( $\mathrm{mg} / \mathrm{kg}$ air-dry diet; retinol 6.4 , cholecalciferol $0.083, \alpha$-tocopherol 22, menadione 0.60 , riboflavin 3.3 , nicotinic acid $16 \cdot 5$, pantothenic acid $5 \cdot 5$, pyridoxine $1 \cdot 1$, biotin, 0.56 , choline 1100 , cyanocobalamin 0.017, Fe 88, Zn 55, Mn 22, Cu 6.6, I 0.22, Se 0.1.

$\S C L A$ nominally contained $55 \mathrm{~g}$ fatty acids as CLA isomers $/ 100 \mathrm{~g}$ total fatty acids.

by first removing the contents of the cannula with a syringe and discarding it. The syringe was then attached to the cannula and blood was withdrawn to ensure unrestricted blood flow. The cannulas were flushed and re-filled after blood collections with anticoagulant (12.5 g K K EDTA/l saline $(0.15 \mathrm{M}-\mathrm{NaCl}))$ and were secured in the pouch.

\section{Challenges}

On the morning of day 8 , half the animals from each dietary treatment were challenged with a dose $(3 \mu \mathrm{g} / \mathrm{kg}$ body weight) of insulin (Astra Pharmaceuticals Pty. Ltd, North Ryde, New South Wales, Australia) diluted in sterile saline $(0.15 \mathrm{M}-\mathrm{NaCl})$. Adrenaline $(1.82 \mathrm{mg}$ adrenaline acid tartrate/ml; Astra Pharmaceuticals Pty. Ltd) diluted in sterile saline $(0.15 \mathrm{M}-\mathrm{HCl})$ was administered to the remaining pigs via the catheter ( $3 \mu \mathrm{g} / \mathrm{kg}$ body weight). The injections were reversed in the afternoon. Both the adrenaline and insulin were injected via the catheter, immediately followed by $5 \mathrm{ml}$ sterile saline. Blood $(5 \mathrm{ml})$ was collected frequently for $1 \mathrm{~h}$ before and $2 \mathrm{~h}$ after each injection. The bleeding for each challenge took place at $-60,-30$, $-15,-1,3,6,10,15,20,30,45,60,90,120$ min relative to the injections. Pre-bleeding for basal samples commenced $30 \mathrm{~min}$ before feed was dispensed for the feeds at 09.00 and 15.00 hours. Plasma glucose and non-esterified fatty acid (NEFA) responses to insulin and adrenaline were determined on day 8 . The following day, the catheters were removed. Whole blood was stored on ice immediately after the bleeding and centrifuged at $2000 \mathrm{~g}$ to separate the plasma. Plasma was portioned into three separate 
vials and stored at $-20^{\circ} \mathrm{C}$ until analysed for metabolite concentrations.

\section{Chemical analysis}

Plasma triacylglycerol concentrations were analysed using an Infinity ${ }^{\mathrm{TM}}$ Triacylglycerol Reagent kit (procedure no. 343; Sigma-Aldrich Pty. Ltd, Castle Hill, New South Wales, Australia). Plasma glucose and urea N concentrations were analysed using a Sigma kit (procedure no. 510 and no. 640 respectively; Sigma-Aldrich Pty. Ltd). Both assays were modified to accommodate the range of concentrations of plasma glucose and plasma urea encountered in the pig. Plasma insulin was measured using a porcine insulin radioimmunoassay kit (catalogue no. PI-12 K; Linco Research, Inc., St Charles, MO, USA). Plasma NEFA levels were assayed using NEFA C ACS-ACOD method (Wako Pure Chemicals Industries Ltd, Doshomachi 3-Chome, Chuo-Ku, Osaka 541, Japan) modified for microtitre plates (Johnson \& Peters, 1993).

\section{Statistical analysis}

The experimental design included four treatment groups in a $2 \times 2$ factorial design. Average daily concentrations of key metabolites and hormones in plasma during the treatment period were compared using a repeated-measures mixed model analysis (Genstat for Windows, version 4.1; Payne et al. 1993). The respective factors were level of dietary CLA ( 0 and $10 \mathrm{~g} / \mathrm{kg})$ and total fat in the diet $(25$ and $100 \mathrm{~g} / \mathrm{kg}$ ) and day. Responses to insulin and adrenaline challenges on day 8 were assessed by comparing the area under the metabolite concentration $v$. time curve. Data were analysed by ANOVA.

\section{Results \\ Growth}

There were no significant effects of CLA on average daily gain $(P=0 \cdot 77)$ or feed conversion ratio $(P=0 \cdot 87)$ (Table 2$)$. By design, the group of pigs fed the high-fat diet consumed significantly less feed per $d$ than the group of pigs fed a low-fat diet $(P=0.006)$, ensuring a similar overall energy intake for the two groups. Feed intake was not significantly reduced by dietary CLA $(P=0 \cdot 11)$.

\section{Effects of dietary fat and conjugated linoleic acid on plasma metabolite levels}

Table 3 shows the average plasma metabolite levels over the first $7 \mathrm{~d}$ of feeding. Plasma NEFA levels in pigs fed the high-fat diet (Table 3) were significantly higher than in pigs fed diets lower in fat $(P<0 \cdot 001)$. Dietary CLA also increased plasma NEFA such that pigs fed CLAsupplemented diets had 10.5 and $5.4 \%$ (for low- and high-fat diets respectively) higher average plasma NEFA levels than pigs fed with basal diets $(P=0.015)$ (Table 3 ). For pigs fed the high-fat diet, the increase in baseline concentrations of NEFA appeared to be most pronounced during the first $2 \mathrm{~d}$ after the commencement of the present study, although this was not indicated by any interaction between dietary CLA and time. The baseline concentration of plasma triacylglycerol was $9 \%$ higher $(P=0 \cdot 008)$ when CLA supplement was added to the diet and $13 \%$ greater $(P=0.001)$ for high- $v$. low-fat diets (Table 3). The increase in plasma triacylglycerol due to CLA supplementation was 11 and $7 \%$ for low- and high-fat diets respectively. There was a linear interaction $(P<0.001)$ between time and dietary fat content such that the plasma triacylglycerol concentrations increased with time in pigs fed the high-fat diet and remained relatively constant in pigs fed the low-fat diet (Table 3).

Plasma glucose concentrations were not affected by dietary CLA treatment $(P=0 \cdot 24)$ or dietary fat $(P=0 \cdot 39)$ treatment (Table 3$)$. Similarly, the average plasma insulin levels were unaffected by dietary CLA $(P=0 \cdot 30)$, but were significantly higher $(P=0.04)$ in pigs fed the lowfat diet compared with pigs fed the high-fat diet (Table $3)$. Plasma urea concentrations were significantly lower $(P=0.001)$ in pigs fed the low-fat diets compared with pigs fed the high-fat diets. The plasma urea concentrations were not significantly reduced $(P=0.13)$ in pigs fed dietary CLA (Table 3).

\section{Adrenaline and insulin challenges}

The plasma NEFA and glucose responses to intravenous

Table 2. Effect of dietary fat and conjugated linoleic acid (CLA) on feed and digestible energy (DE) intake in finisher pigs*

(Mean values for $7 \mathrm{~d}$ of feeding)

\begin{tabular}{|c|c|c|c|c|c|c|c|c|}
\hline \multirow{2}{*}{$\begin{array}{l}\text { Fat }(\mathrm{g} / \mathrm{kg}) \ldots \\
\text { CLA-55 }(\mathrm{g} / \mathrm{kg}) \dagger \ldots\end{array}$} & \multicolumn{2}{|c|}{25} & \multicolumn{2}{|c|}{100} & \multirow[b]{2}{*}{ SED } & \multicolumn{3}{|c|}{$\begin{array}{c}\text { Statistical significance of } \\
\text { effect: } P\end{array}$} \\
\hline & 0 & 10 & 0 & 10 & & $\mathrm{C}$ & $\mathrm{F}$ & $\mathrm{C} \times \mathrm{F}$ \\
\hline Rate of gain $(\mathrm{kg} / \mathrm{d})$ & 0.98 & 0.84 & 0.84 & 0.92 & 0.13 & 0.77 & 0.77 & 0.27 \\
\hline DE intake (MJ/d) & 37.5 & 35.4 & 35.4 & 34.4 & 1.65 & 0.11 & 0.32 & 0.87 \\
\hline Feed intake (kg/d) & 2.54 & 2.40 & $2 \cdot 28$ & $2 \cdot 17$ & 0.11 & 0.11 & 0.006 & 0.82 \\
\hline Feed:gain & 2.64 & 3.05 & $2 \cdot 89$ & $2 \cdot 39$ & 0.47 & 0.83 & 0.60 & 0.20 \\
\hline
\end{tabular}

C, dietary effect of CLA; $F$, effect of dietary fat

${ }^{*}$ For details of diets and procedures, see Table 1 and p. 626.

† CLA nominally contained $55 \mathrm{~g}$ fatty acids as CLA isomers $/ 100 \mathrm{~g}$ total fatty acids.

$\ddagger$ Standard error of the difference for $\mathrm{C} \times \mathrm{F}$. 
Table 3. Effect of dietary fat and conjugated linoleic acid (CLA) on plasma constituents in finisher pigs *

\begin{tabular}{|c|c|c|c|c|c|c|c|c|c|c|c|c|c|}
\hline & \multirow[b]{2}{*}{ Fat $(\mathrm{g} / \mathrm{kg})$} & \multirow[b]{2}{*}{ CLA-55 $(\mathrm{g} / \mathrm{kg}) \dagger$} & \multicolumn{7}{|c|}{ Day } & \multirow[b]{2}{*}{ SED $\ddagger$} & \multicolumn{3}{|c|}{$\begin{array}{c}\text { Statistical significance of } \\
\text { effects: } P \S\end{array}$} \\
\hline & & & 1 & 2 & 3 & 4 & 5 & 6 & 7 & & C & $\mathrm{F}$ & $\mathrm{D}$ \\
\hline \multirow[t]{4}{*}{ NEFA $(\mu \mathrm{mol} / \mathrm{l})$} & 25 & 0 & $87 \cdot 1$ & $69 \cdot 6$ & $71 \cdot 4$ & 81.5 & $82 \cdot 8$ & $76 \cdot 2$ & 82.9 & $7 \cdot 17$ & 0.015 & $<0.001$ & $<0.001$ \\
\hline & & 10 & 93.4 & $75 \cdot 8$ & 82.9 & 88.2 & 88.9 & 85.3 & $101 \cdot 3$ & & & & \\
\hline & 100 & 0 & 129.9 & 109.5 & $119 \cdot 1$ & 124.3 & 118.9 & $116 \cdot 8$ & $146 \cdot 1$ & & & & \\
\hline & & 10 & 145.8 & 120.5 & 119.6 & 128.2 & 124.3 & 126.6 & 145.0 & & & & \\
\hline \multirow[t]{4}{*}{ Triacylglycerol $(\mathrm{mmol} / \mathrm{l}) \|$} & 25 & 0 & $20 \cdot 6$ & $20 \cdot 2$ & 20.6 & 21.6 & 21.8 & $21 \cdot 7$ & 21.6 & 1.75 & 0.008 & $<0.001$ & $<0.001$ \\
\hline & & 10 & $23 \cdot 6$ & $21 \cdot \overline{8}$ & 23.1 & 23.7 & $25 \cdot 8$ & $25 \cdot 1$ & 23.1 & & & & \\
\hline & 100 & 0 & $25 \cdot 1$ & 22.4 & $22 \cdot 0$ & 23.9 & $25 \cdot 7$ & 29.5 & 25.5 & & & & \\
\hline & & 10 & 22.6 & 23.9 & 24.0 & 26.0 & 29.1 & $32 \cdot 3$ & 29.2 & & & & \\
\hline \multirow[t]{4}{*}{ Glucose $(\mathrm{mmol} / \mathrm{l})$} & 25 & 0 & $5 \cdot 60$ & $5 \cdot 30$ & $5 \cdot 24$ & 5.48 & $5 \cdot 61$ & 5.43 & 5.51 & 0.177 & 0.24 & 0.39 & 0.21 \\
\hline & & 10 & 5.42 & $5 \cdot 21$ & $5 \cdot 50$ & $5 \cdot 34$ & 5.48 & 5.40 & 5.52 & & & & \\
\hline & 100 & 0 & 5.62 & $5 \cdot 54$ & 5.70 & $5 \cdot 67$ & 5.55 & 5.59 & 5.58 & & & & \\
\hline & & 10 & 5.49 & 5.47 & $5 \cdot 35$ & $5 \cdot 33$ & 5.46 & $5 \cdot 40$ & 5.43 & & & & \\
\hline \multirow[t]{4}{*}{ Insulin $(\mathrm{mU} / \mathrm{ml})$ 9 } & 25 & 0 & 13.9 & $13 \cdot 4$ & $13 \cdot 8$ & $15 \cdot 0$ & 26.7 & 12.5 & $15 \cdot 7$ & 4.02 & 0.30 & 0.039 & $<0.001$ \\
\hline & & 10 & $16 \cdot 2$ & 14.9 & 14.5 & $15 \cdot 2$ & 24.9 & 19.7 & $20 \cdot 2$ & & & & \\
\hline & 100 & 0 & $12 . \overline{5}$ & $12 \cdot 1$ & $12 \cdot 8$ & $12 \cdot \overline{4}$ & 11.7 & 10.7 & 11.5 & & & & \\
\hline & & 10 & 9.8 & 13.8 & $13 \cdot 3$ & $14 \cdot 3$ & $16 \cdot 2$ & 13.2 & $16 \cdot 6$ & & & & \\
\hline \multirow[t]{4}{*}{ Urea (mg/l) } & 25 & 0 & $52 \cdot 9$ & $54 \cdot 2$ & $55 \cdot 2$ & $56 \cdot 6$ & 55.5 & 58.5 & $57 \cdot 3$ & 3.39 & 0.13 & $<0.001$ & 0.37 \\
\hline & & 10 & 45.5 & 42.8 & 40.5 & $40 \cdot 3$ & $40 \cdot 6$ & 43.2 & 39.6 & & & & \\
\hline & 100 & 0 & 55.1 & $57 \cdot 3$ & 55.4 & 53.9 & 57.7 & $58 \cdot 8$ & $56 \cdot 6$ & & & & \\
\hline & & 10 & $47 \cdot 3$ & $45 \cdot 8$ & 47.4 & 47.9 & $45 \cdot 5$ & 47.7 & 46.9 & & & & \\
\hline
\end{tabular}

C, effect of dietary CLA; F, effect of dietary fat; D, effect of day of treatment; NEFA, non-esterified fatty acid.

* Results presented for each day represent the mean value of eight samples taken at $3 \mathrm{~h}$ intervals for days 1,2 and 7 and two samples taken $9 \mathrm{~h}$ apart on days $3,4,5$ and 6 . For details of diets and procedures, see

Table 1 and $\mathrm{p}$. 626 .
†CLA nominally contained $55 \mathrm{~g}$ fatty acids as CLA isomers $/ 100 \mathrm{~g}$ total fatty acids.

¥ Standard error of the difference for $\mathrm{C} \times \mathrm{F} \times \mathrm{D}$.

$\S$ There were no interactions (all $P>0.20$ ) except where indicated.

I $F \times D$ interaction, $P=0.042$ (for details, see $p .627$ ). 
adrenaline or insulin injection are shown in Figs. 1-4. The metabolic responses to both of these homeostatic signals were evident within minutes, before quickly returning to the levels recorded prior to the challenge. The calculated areas under the metabolite time curves are presented in Table 4. The intravenous injection of adrenaline stimulated lipolysis, as shown by an acute increase in plasma NEFA levels in all pigs. The lipolytic response, as indicated by

(a)

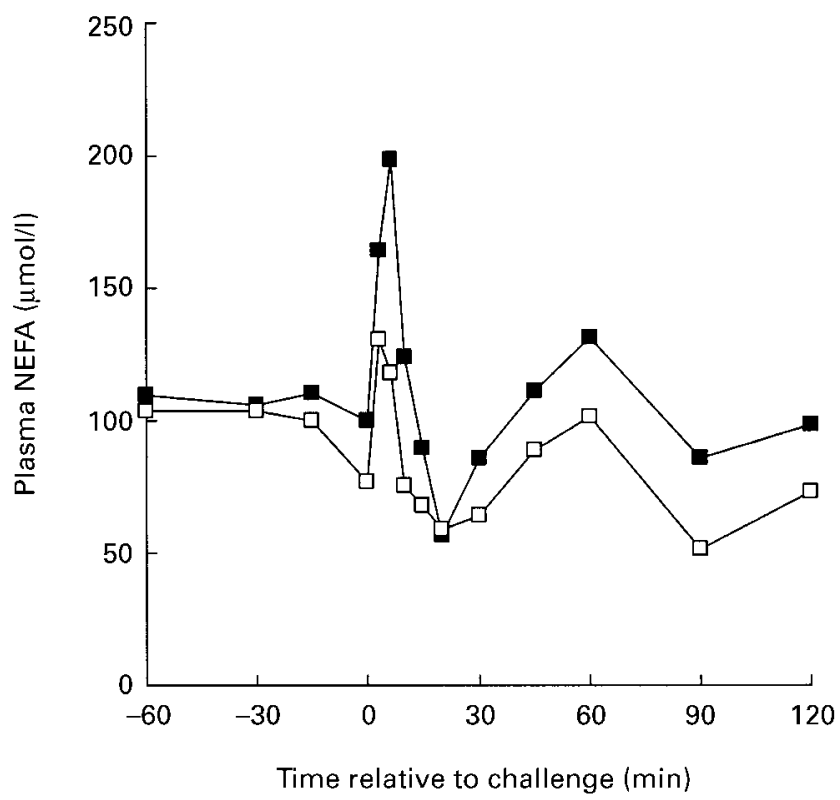

(b)

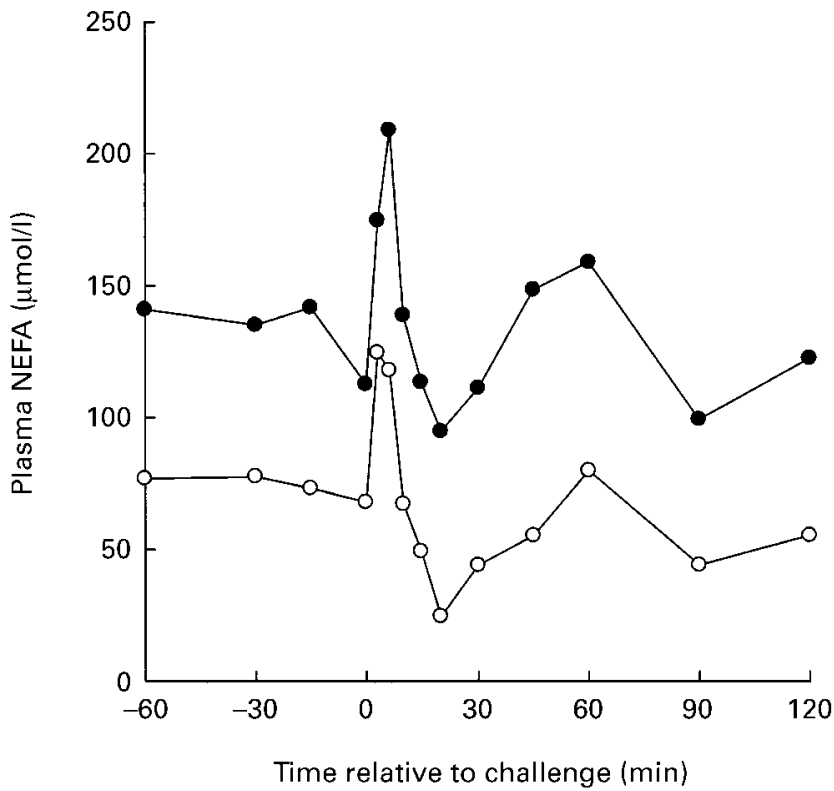

Fig. 1. Effect of (a), dietary conjugated linoleic acid (CLA) and (b), fat on plasma non-esterified fatty acids (NEFA) concentration and responses to adrenaline $(3 \mu \mathrm{g} / \mathrm{kg})$ in finisher pigs. ( $\square)$, No CLA; $(\square)$, $\mathrm{CLA}$; (O), low fat; $(\bullet)$, high fat. Studies were conducted after $8 \mathrm{~d}$ of dietary treatment. For details of diets and procedures, see p. 626. Since there were no interactions between dietary treatments only the main effects are shown. The standard error of the difference for a two-way comparison (dietary treatment $\times$ time) was $13.2 \mu \mathrm{mol} / \mathrm{l}$. area under the curve corrected for baseline, was significantly higher $(P=0.018)$ in pigs fed dietary CLA than in pigs fed the basal diets (Table 4, Fig. 1(a)). Prior to the injection of adrenaline, the basal plasma NEFA concentrations were significantly $(P<0.02)$ higher in pigs fed the high-fat diet. After the adrenaline challenge, the increase in NEFA area under the curve was similar

(a)

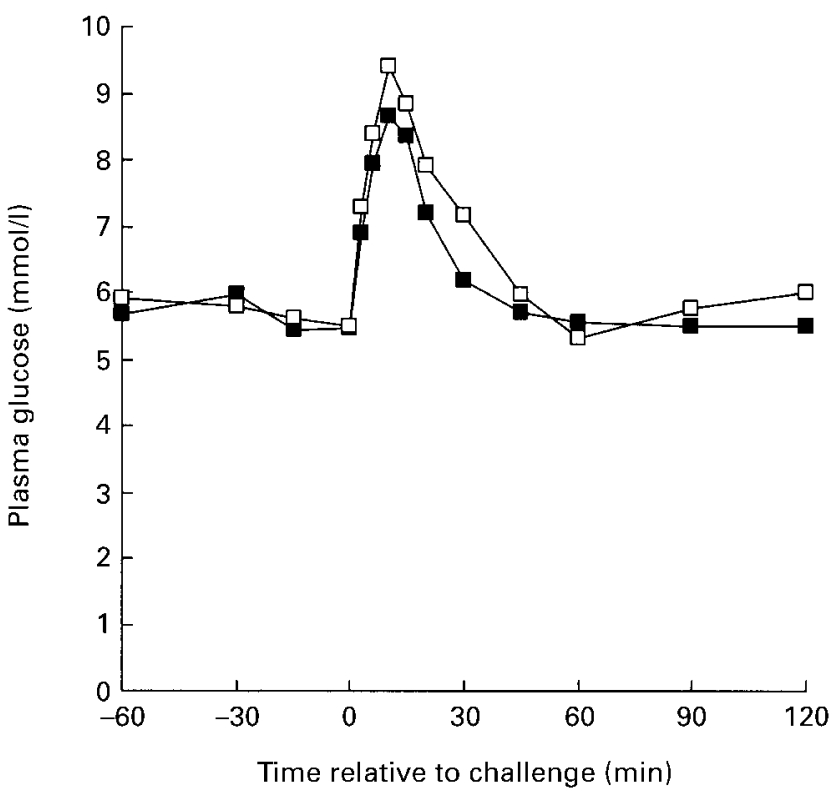

(b)

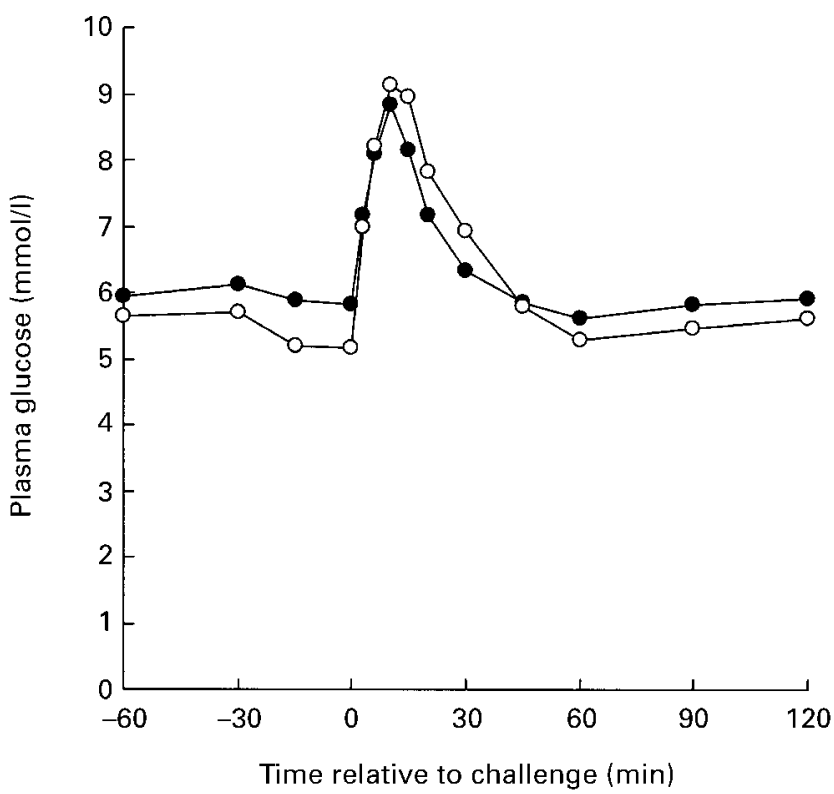

Fig. 2. Effect of (a), dietary conjugated linoleic acid (CLA) and (b), fat on plasma glucose concentration and responses to adrenaline

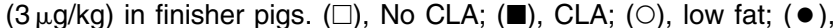
high fat. Studies were conducted after $8 \mathrm{~d}$ of dietary treatment. For details of diets and procedures, see p. 626. Since there were no interactions between dietary treatments only the main effects are shown. The standard error of the difference for a two-way comparison (dietary treatment $\times$ time) was $0.195 \mathrm{mmol} / \mathrm{l}$. 
(a)

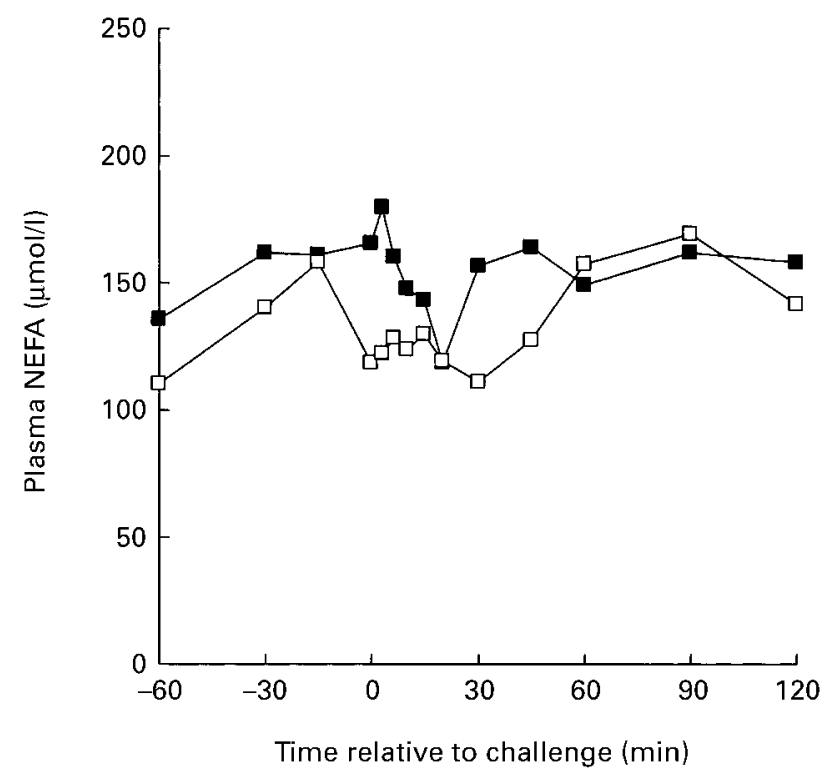

(b)

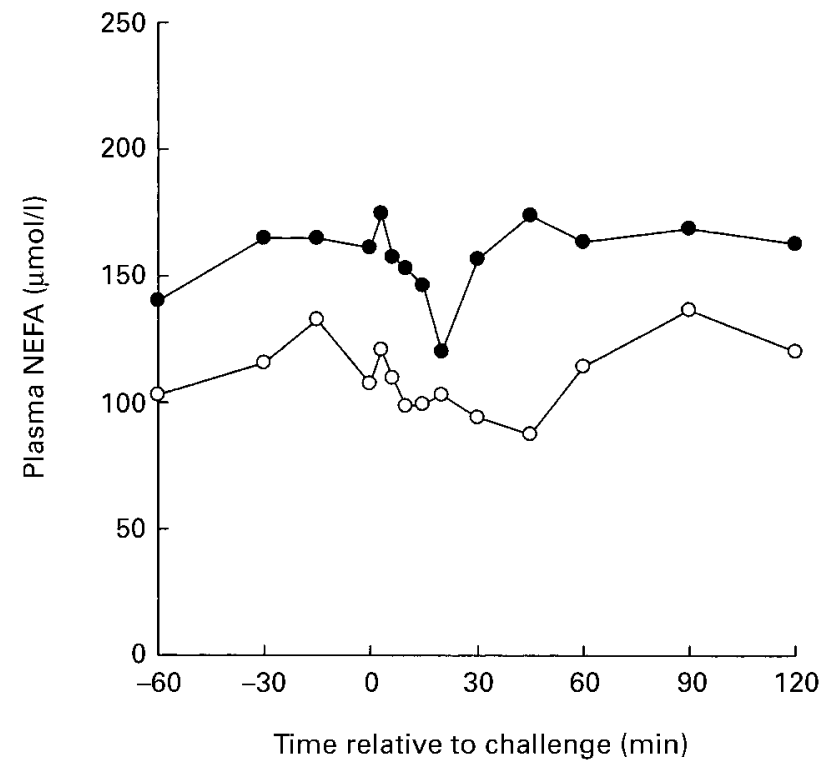

Fig. 3. Effect of (a), dietary conjugated linoleic acid (CLA) and (b), fat on plasma non-esterified fatty acids (NEFA) concentration and responses to insulin $(3 \mu \mathrm{g} / \mathrm{kg})$ in finisher pigs. ( $\square)$, No CLA; ( $\square$ ), $\mathrm{CLA} ;(\mathrm{O})$, low fat; $(\bullet)$, high fat. Studies were conducted after $8 \mathrm{~d}$ of dietary treatment For details of diets and procedures, see p. 626. Since there were no interactions between dietary treatments only the main effects are shown. The standard error of the difference for a two-way comparison (dietary treatment $\times$ time) was $7.58 \mu \mathrm{mol} / \mathrm{l}$.

$(P=0.78)$ to that of pigs fed the low-fat diet (Fig. 1(b)). The intravenous injection of adrenaline caused mild hyperglycaemia as shown by an increase in plasma glucose area under the curve in all dietary treatments (Fig. 2). Plasma glucose area under the curve after adrenaline injection was significantly reduced $(34-41 \%, P=0.007)$ in pigs fed the high-fat diet, but not significantly reduced (17$26 \%, P=0.12$ ) by dietary CLA (Table 4 ).

The anti-lipolytic effects of insulin were relatively (a)

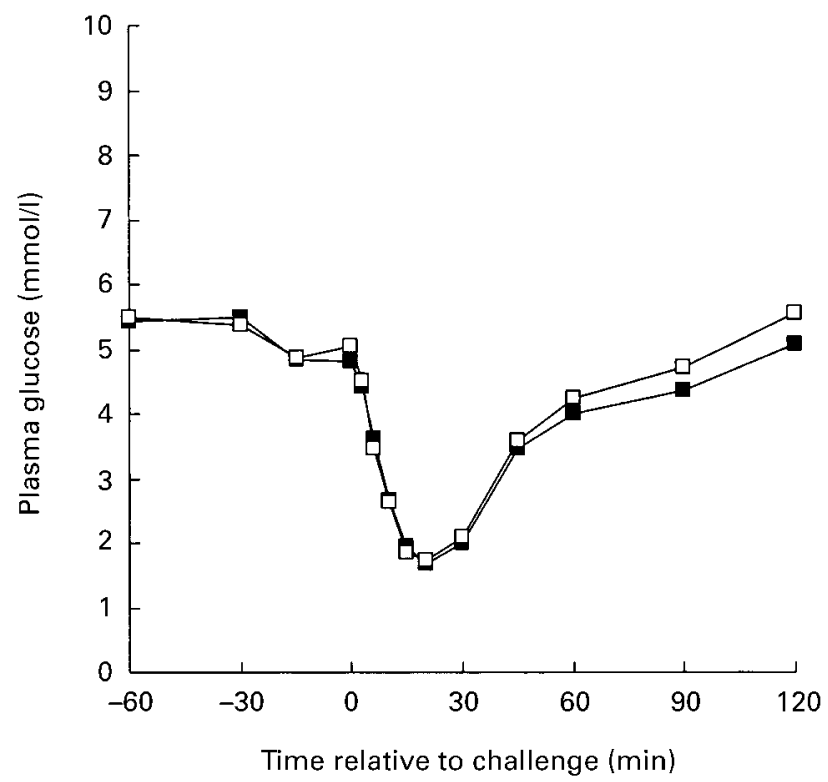

(b)

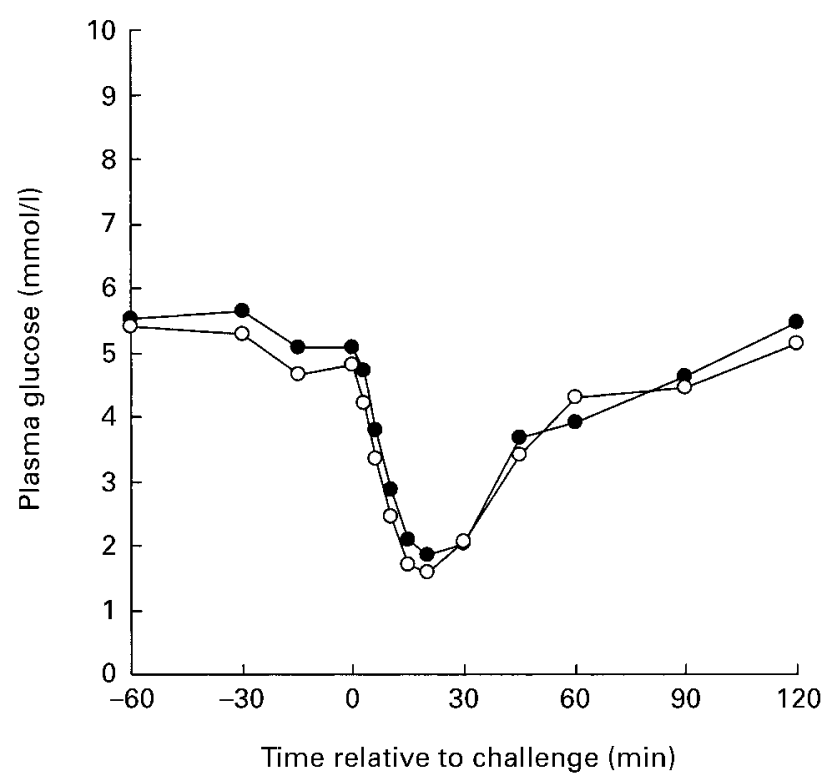

Fig. 4. Effect of (a), dietary conjugated linoleic acid (CLA) and (b), fat on plasma glucose concentration and responses to insulin $(3 \mu \mathrm{g} / \mathrm{kg})$ in finisher pigs. ( $\square)$, No CLA; $(\square)$, CLA; $(O)$, low fat; $(\bullet)$, high fat. Studies were conducted after $8 \mathrm{~d}$ of dietary treatment. For details of diets and procedures, see p. 626. Since there were no interactions between dietary treatments only the main effects are shown. The standard error of the difference for a two-way comparison (dietary treatment $\times$ time) was $0.178 \mathrm{mmol} / \mathrm{l}$.

modest (Fig. 3). Although there was a significantly greater $(P=0.036)$ plasma NEFA area under the curve in response to insulin over the first 6 min of the challenge in pigs fed CLA, the area under the curve was not significantly different over the interval between 0 and 20 min after the challenge (Fig. 3(a), Table 4). There was no significant difference in plasma NEFA response $(P=0.98)$ between pigs fed different levels of dietary fat (Table 4$)$. On the 
Table 4. Effect of dietary fat and conjugated linoleic acid (CLA) on metabolite responses to insulin and adrenaline in finisher pigs*

\begin{tabular}{|c|c|c|c|c|c|c|c|c|}
\hline \multirow{2}{*}{$\begin{array}{l}\text { Fat }(\mathrm{g} / \mathrm{kg}) \ldots \\
\text { CLA-55 }(\mathrm{g} / \mathrm{kg}) \dagger \ldots\end{array}$} & \multicolumn{2}{|c|}{25} & \multicolumn{2}{|c|}{100} & \multirow[b]{2}{*}{ SED $¥$} & \multicolumn{3}{|c|}{$\begin{array}{c}\text { Statistical significance of } \\
\text { effect: } P\end{array}$} \\
\hline & 0 & 10 & 0 & 10 & & C & $\mathrm{F}$ & $\mathrm{C} \times \mathrm{F}$ \\
\hline \multicolumn{9}{|l|}{ Response to adrenaline } \\
\hline Plasma NEFA $(\mu \mathrm{mol} . \mathrm{min} / \mathrm{l}) \S$ & 88 & 260 & 135 & 243 & 73 & 0.018 & 0.78 & 0.55 \\
\hline Plasma glucose $(\mathrm{mmol} \cdot \mathrm{min} / \mathrm{l}) \|$ & 81 & 67 & 53 & 39 & 12 & 0.12 & 0.007 & 0.98 \\
\hline \multicolumn{9}{|l|}{ Response to insulin } \\
\hline Plasma NEFA $(\mu \mathrm{mol} . \mathrm{min} /) \S$ & -49 & 40 & -43 & 32 & 49 & 0.036 & 0.98 & 0.84 \\
\hline Plasma glucose $(\mathrm{mmol} . \mathrm{min} / \mathrm{l}) \|$ & -81 & -76 & -73 & -80 & 11 & 0.86 & 0.84 & 0.43 \\
\hline
\end{tabular}

$C$, effect of dietary CLA; F, effect of dietary fat; NEFA, non-esterified fatty acid.

${ }^{*}$ For details of diets and procedures, see Table 1 and p. 626.

† CLA nominally contained $55 \mathrm{~g}$ fatty acids as CLA isomers $/ 100 \mathrm{~g}$ total fatty acids.

$\ddagger$ Standard error of the difference for $\mathrm{C} \times \mathrm{F}$

$\S$ Sum of response over first $6 \mathrm{~min}$.

॥ Sum of response over first $30 \mathrm{~min}$.

other hand, there was a marked hypoglycaemia in response to insulin injection (Fig. 4) although there was no effect of either dietary CLA $(P=0.86)$ or fat $(P=0.84)$ on the magnitude of this response (Fig. 4, Table 4).

\section{Discussion}

The present study was designed to investigate the interactions between dietary energy source and CLA using catheterised pigs. While growth performance data are notoriously unreliable over short periods, it is worth reporting that there were no significant effects of CLA on average daily gain or feed conversion ratio over the $8 \mathrm{~d}$ of the study. In addition, no significant interactions were observed between CLA and the fat content in the diet for daily gain, energy intake or feed intake. However, feed intake tended to be reduced $(-5 \%)$ by dietary CLA, although this was not significant $(P=0 \cdot 11)$. Other studies have reported a reduction in feed intake associated with CLA feeding in mice, in particular in the early stages (the first 3 weeks) of feeding relatively high levels of CLA ( $>10 \mathrm{~g} / \mathrm{kg})$ (West et al. 1998). However, the small suppression in energy intake associated with CLA treatment could not be entirely responsible for the large loss of body fat content in mice reported by West et al. (1998) as well as the reduction in fat accretion in pigs (Ostrowska et al. 1999). Other possible mechanisms involved include the inhibition of fat deposition from both preformed fatty acids (lipogenesis) or glucose (de novo lipogenesis) and/or an increase in fat mobilisation (lipolysis) in pigs fed dietary CLA. Plasma metabolites and hormones as well as acute responses to homeostatic hormones that may indicate changes in these three possible mechanisms for reduced fat accretion in pigs fed CLA were therefore investigated in the present study.

\section{Evidence of reduced rate of lipogenesis}

Given that pigs are generally fed a high-carbohydrate diet (Dunshea et al. 1992a), de novo lipogenesis, a process whereby carbohydrates are converted to triacylglycerol and stored in the adipose tissue, would represent the major mechanism for lipid synthesis (Dunshea et al. 1992a). Thus, intuitively, it would be likely that CLA acts to reduce the rate of de novo lipogenesis. However, West et al. (1998) reported that the carcass fat content was decreased in CLA-treated mice regardless of whether they were fed either a high-carbohydrate or a high-fat diet. The metabolic results from the present study also showed no significant interactions between the dietary CLA and the total fat contents, suggesting that CLA exerts similar effects in pigs fed either a high-carbohydrate or a high-fat diet. Hence, in both studies the rates of de novo synthesis as well as the use of preformed fatty acids might be reduced by dietary CLA.

In order to study fat transport and metabolism, the key metabolites and hormones (including triacylglycerol, NEFA, glucose and insulin) involved in the process of lipid synthesis were monitored during CLA supplementation. Fatty acids for lipogenesis can be produced de novo, principally from glucose in adipose tissue, and the uptake of glucose into skeletal muscle and adipose tissue is regulated by insulin (Dunshea et al. 1992b). Therefore, changes in the rate of lipid deposition may be reflected in the levels of these plasma metabolites. For example, pigs fed the high-fat diet had higher plasma triaclyglycerol concentrations than pigs fed the low-fat diet (Table 3). In turn, this may have resulted in the higher rate of hydrolysis of circulating triacylglycerol originating from the high-fat diet, hence the higher circulating plasma NEFA levels (Table 3).

Pigs fed the CLA-containing diets had higher plasma NEFA concentrations than the pigs fed diets without CLA, regardless of dietary fat content, and this response appeared to be most pronounced over the first $2 \mathrm{~d}$ of CLA feeding. One of the contributing factors could be a reduced uptake of the NEFA resulting from hydrolysis of circulating triacylglycerol catalysed by lipoprotein lipase at the epithelial cell surface. A reduced uptake of preformed fatty acids is clearly indicated by the higher levels of circulating triacylglycerol in pigs fed diets containing CLA, despite the tendency towards a reduced feed intake, and thus dietary fat intake, in these pigs. Likewise, others have also found a substantial, although 
non-significant increase $(24 \%)$ in serum triacylglycerol in pigs fed CLA (O'Quinn et al. 1998; Stangl et al. 1999). An increase in plasma triacylglycerol levels in pigs fed supplemental CLA could be an indication of reduced activity of lipoprotein lipase. In this context, Park et al. (1997) found that CLA decreased the heparin-releasable lipoprotein lipase activity in 3T3-L1 cultured murine adipocytes. Therefore, it is reasonable to hypothesise that a major effect of CLA on fat accretion is via decreased lipid synthesis from preformed fatty acids possibly through reduced lipoprotein lipase activity.

Investigations with lactating cows indicate that the major effect of CLA on milk fat synthesis is due to a reduced rate of de novo synthesis (Chouinard et al. 1999; Baumgard et al. 2001b). CLA was also shown to reduce the mRNA abundance of lipogenic enzymes including acetyl-CoA carboxylase and fatty acid synthetase, two key enzymes in de novo fatty acid synthesis, in adipose tissue of growing mice (Tsuboyama-Kasaoka et al. 2000) and in lactating cows (Baumgard et al. 2001a). However, there was no change in enzyme activity in weaned pigs fed CLA (Bee, 2000). To investigate this further, the level of plasma glucose, which is the primary substrate for de novo lipid synthesis, was monitored in the present study. The uptake of glucose is dependent upon insulin, hence the level of this hormone was also examined. In the present study, dietary CLA had little effect upon plasma insulin concentrations. Furthermore, no hyperglycaemic responses were evident throughout the study indicating that glucose production and utilisation were not markedly influenced by dietary CLA. However, the insulin:glucose ratio, which is used as a measure of insulin sensitivity in rodents and human subjects (Legro et al. 1998; Harder et al. 1999) tended to increase $(P=0 \cdot 13)$ with dietary CLA, particularly in pigs fed the low-fat diet. While this may be indicative of slight insulin resistance, it was definitely not comparable with that observed in rodents (DeLany \& West, 2000; Tsuboyama-Kasaoka et al. 2000).

The rates of glucose clearance, and by inference a component of lipogenesis, were further studied by intravenous infusion of insulin. Insulin, a hormone secreted by the $B$ cells of the pancreas, plays a predominant role in the lipogenic process. When challenged with insulin, pigs fed the CLA-supplemented diets appeared to be relatively resistant to the anti-lipolytic effects of insulin, as indicated by little change in plasma NEFA concentrations over the first $6 \mathrm{~min}$ after insulin injection. On the other hand, plasma NEFA concentrations did decrease, albeit only slightly, in response to insulin injection in the pigs fed diets containing no CLA. The marginal NEFA responses to insulin are consistent with very low rates of basal lipolysis in the growing pig (Dunshea et al. 1992c) and under these conditions, it is very difficult to demonstrate an anti-lipolytic effect of insulin (Dunshea et al. 1992c; Dunshea \& King, 1995). Given the significant, but moderate, difference in NEFA response between pigs fed different CLA levels, it is perhaps judicious not to place too much emphasis on effects of CLA on insulin responses, particularly given the failure to observe any difference in glucose metabolism after insulin injection.

Plasma glucose clearance after insulin challenge was not altered by CLA treatment indicating no change in wholebody response in glucose uptake. Studies in pre-diabetic Zucker fatty rats have shown that only at higher concentrations of supplemental CLA isomer mix $(15 \mathrm{~g} / \mathrm{kg})$ is there any improvement in glucose tolerance and insulin sensitivity, due to increased uptake of glucose and insulin levels in skeletal muscle (Houseknecht et al. 1998). Houseknecht et al. (1998) proposed that CLA induced the peroxisome proliferator-activated receptor expression, most probably proliferator-activated receptor- $\gamma$, a key regulator of insulin sensitivity. The same group of researchers (Ryder et al. 2001) later attributed these responses to the trans-10,cis-12-CLA isomer. It should also be noted that effects of CLA on insulin sensitivity are more likely to be observed in animals with metabolic disorders, such as in the Zucker rat, rather than in normal animals as used in the present study. In this context, recent studies in lactating cows showed that abomasal infusion of trans-10, cis12-CLA isomer had no effect on the plasma glucose response to an insulin challenge (Baumgard et al. 2002).

\section{Evidence of increased rate of lipolysis}

It is also possible that CLA could exert its effect on lipolysis. The triacylglycerol within the adipocyte can be hydrolysed by hormone sensitive lipase into NEFA and glycerol (Pethick \& Dunshea, 1993). The rate of fat mobilisation may be sufficiently increased to result in the net reduction in lipid accretion observed in pigs fed dietary CLA.

Therefore, the small, but significant $(P=0.015)$ increase in plasma NEFA in the CLA-fed pigs could be due to increased fat breakdown and enhanced rate of movement of fatty acids into $\beta$-oxidation for ATP production. In vitro work with 3T3-L1 adipose cells supported the evidence that CLA potentially enhanced lipolysis and it was attributed to an increase of the carnitine palmitoyl transferase activity, both in the adipose tissue of the fed animals and in the skeletal muscle of fasted mice (Park et al. 1997). If increased fat mobilisation was the source of increased plasma NEFA in CLA-fed pigs, it would only be a very small component (about $6 \mathrm{~g} / \mathrm{d}$ ) (Dunshea et al. $1992 a, b)$ of the reduction $(86 \mathrm{~g} / \mathrm{d})$ in fat accretion in pigs fed this level of CLA (Ostrowska et al. 1999) based on the relationship between plasma NEFA concentrations and NEFA turnover rate (Dunshea et al. 1992c). Hence, it is unlikely that the major component of the reduced fat deposition due to CLA supplementation is a result of increased lipolysis. In this context, there was no change in plasma NEFA in lactating cows infused with the trans-10,cis-12-CLA isomer (Baumgard et al. 2002).

An additional indication of an increase in adipose tissue fat mobilisation during CLA feeding was provided by the greater increase $(+126 \%)$ in plasma NEFA after an intravenous adrenaline injection on day 8 of the study (Fig. 3 ). Since the plasma NEFA response to adrenaline is an indicator of B-adrenergic stimulated lipolysis (Sechen et al. 1990; Dunshea et al. 1995; Dunshea \& King, 1995), these results suggest that this response was heightened during CLA feeding. In dairy cows, infusion of trans10,cis-12-CLA, the biologically active isomer that causes 
a marked reduction in milk fat synthesis, had little effect on NEFA concentrations (basal lipolysis) or circulating leptin concentrations. However, modest reductions (24-33\%) in the NEFA response to an adrenaline challenge were observed in two investigations where cows were treated with the trans-10,cis-12-CLA isomer compared with the control and treatment with cis-9,trans-11-CLA (Baumgard et al. 2002). Hence, there was no indication of increased fat mobilisation in lactating cows abomasally infused with trans-10,cis-12-CLA isomer. In the present study, pigs received a mixture of CLA isomers that was particularly enriched with both cis-9,trans-11- and the trans-10,cis12-CLA isomers, which may in part explain the differences. In addition, adipose tissue from lactating dairy cows is much more sensitive (10-100-fold) to catecholamines than adipose tissue from growing pigs (Pethick \& Dunshea, 1993). Thus, although the studies used similar doses of adrenaline they would have been conducted on the ascending phase and plateau phase of the doseresponse curve in pigs and cows respectively. Therefore, dietary CLA may have increased sensitivity to adrenaline in pigs (present study) while decreasing maximal responsiveness in cows (Baumgard et al. 2000, 2001a), two scenarios that are not mutually exclusive. Regardless, it is still unlikely that increased fat mobilisation is a major proportion of the reduction in fat deposition during dietary CLA supplementation in pigs.

After adrenaline injection, the plasma glucose levels in pigs fed diets high in fat and CLA-fed pigs were lower than the control pigs, suggesting that there might be small changes in the ability of the pig liver to respond to adrenergic stimulation due to dietary fat and CLA. The importance of these metabolic adaptations to dietary fat and CLA supplementation is unknown.

\section{Conclusion}

In conclusion, results from the present study suggest that there were no interactions between dietary energy source and CLA. Dietary CLA-reduced fat accretion in pigs appears to be largely due to a reduced rate of lipogenesis from preformed fatty acids, possibly through reduced lipoprotein lipase activity, and to lesser extent, increased lipolysis. Results from the present study show that plasma triacylglycerol and NEFA concentrations are increased during CLA feeding in pigs suggesting alterations in both the uptake of pre-formed fatty acids and fat breakdown. However, defining the mechanism(s) of CLA requires a more definitive understanding of specific dimensions of lipid metabolism that are responding to CLA treatment. Further, studies are needed to determine activities of key lipogenic enzymes involved in the lipid transport and metabolism in adipose tissue from CLA-treated pigs.

\section{Acknowledgements}

The present study was supported by Australian Pork Limited. E. O. gratefully acknowledges a Swinburne University Postgraduate Research Award and an Australian Pork Limited Postgraduate 'Top-up' Scholarship.

\section{References}

Albright K, Liu KL, Storkson JM, Hentges E, Lofgren P, Simeca J, Cook ME \& Pariza M (1996) Body composition repartitioning following the removal of dietary conjugated linoleic acid. Journal of Animal Science 74, 152.

Baumgard LH, Corl BA, Dwyer DA \& Bauman DE (2002) Effects of conjugated linoleic acid (CLA) on tissue response to homeostatic signals and plasma variables associated with lipid metabolism in lactating dairy cows. Journal of Animal Science 80, 1285-1293.

Baumgard LH, Matitashvili E, Corl BA, Dwyer DA \& Bauman DE (2001a) trans-10,cis-12 CLA decreases lipogenic rates and expression of genes involved in milk lipid synthesis in dairy cows. Journal of Dairy Science (In the Press).

Baumgard LH, Sangster JK \& Bauman DE (2001b) Milk fat synthesis is progressively reduced by increasing supplemental amounts of trans-10,cis-12 conjugated linoleic acid (CLA). Journal of Nutrition 131, 1764-1769.

Bee G (2000) Dietary conjugated linoleic acid consumption during pregnancy and lactation influences growth and tissue composition in weaned pigs. Journal of Nutrition 130, 2981-2989.

Boisclair YR, Bauman DE, Bell AW, Dunshea FR \& Harkins M (1994) Nutrient utilization and protein turnover in the hindlimb of cattle treated with bovine somatotropin. Journal of Nutrition 124, 664-673.

Chouinard PY, Corneau L, Barbano DM, Metzger LE \& Bauman DE (1999) Conjugated linoleic acids alter milk fatty acid composition and inhibit milk fat secretion in dairy cows. Journal of Nutrition 129, 1579-1584.

DeLany JP, Blohm F, Truett AA, Scimeca JA \& West DB (1999) Conjugated linoleic acid rapidly reduces body fat content in mice without affecting energy intake. American Journal of Physiology 276, R1172-R1179.

DeLany JP \& West DB (2000) Changes in body composition with conjugated linoleic acid. Journal of American College of Nutrition 19, 487S-493S.

Dunshea FR, Bauman DE, Boyd RD \& Bell AW (1992a) Temporal response of circulating metabolites and hormones during somatotropin treatment of growing pigs. Journal of Animal Science 70, 123-131.

Dunshea FR, Boisclair YR, Bauman DE \& Bell AW (1995) Effects of bovine somatotropin and insulin on whole-body and hindlimb glucose metabolism in growing steers. Journal of Animal Science 73, 2263-2271.

Dunshea FR, Harris DM, Bauman DE, Boyd RD \& Bell AW (1992b) Effect of porcine somatotropin on in vivo glucose kinetics and lipogenesis in growing pigs. Journal of Animal Science 70, 141-151.

Dunshea FR, Harris DM, Bauman DE, Boyd RD \& Bell AW $(1992 c)$ Effect of somatotropin on nonesterified fatty acid and glycerol metabolism in growing pigs. Journal of Animal Science 70, 132-140.

Dunshea FR \& King RH (1994) Temporal response of plasma metabolites to ractopamine treatment in the growing pig. Australian Journal of Agricultural Research 45, 1683-1692.

Dunshea FR \& King RH (1995) Responses to homeostatic signals in ractopamine-treated pigs. British Journal of Nutrition 73, 809-818.

Harder T, Rake A, Rohde W, Doerner G \& Plagemann A (1999) Overweight and increased diabetes susceptibility in neonatally insulin-treated adult rats. Endocrine Regulations 33, 25-31.

Houseknecht KL, Vanden Heuvel JP, Moya-Camarena SY, Portocarrero CP, Peck LW, Nickel KP \& Belury MA (1998) Dietary conjugated linoleic acid normalizes impaired glucose tolerance 
in the Zucker diabetic fatty fa/fa rat. Biochemical and Biophysical Research Communications 244, 678-682.

Johnson MM \& Peters JP (1993) Technical note: an improved method to quantify nonesterified fatty acids in bovine plasma. Journal of Animal Science 71, 753-756.

Legro RA, Finegood D \& Dunaif A (1998) A fasting glucose to insulin ratio is a useful measure of insulin sensitivity in women with polycystic ovary syndrome. Journal of Clinical Endocrynology and Metabolism 83, 2694-2698.

O'Quinn PR, Sith JW, Nelssen JL, Tokach MD, Goodband RD \& Owen KQ (1998) A comparison of modified tall oil and conjugated linoleic acid on growing-finishing pig growth performance and carcass characteristics. Journal of Animal Science 76, Suppl. 2, 61.

Ostrowska E, Muralitharan M, Cross RF, Bauman DE \& Dunshea FR (1999) Dietary conjugated linoleic acids increase lean tissue and decrease fat deposition in growing pigs. Journal of Nutrition 129, 2037-2042.

Park Y, Albright KJ, Liu W, Storkson JM, Cook ME \& Pariza MW (1997) Effect of conjugated linoleic acid on body composition in mice. Lipids 32, 853-858.

Park Y, Albright KJ, Storkson JM, Liu W, Cook ME \& Pariza MW (1999a) Changes in body composition in mice during feeding and withdrawal of conjugated linoleic acid. Lipids 34, 243-248.

Park Y, Storkson JM, Albright KJ, Liu W \& Pariza MW (1999b) Evidence that the trans-10,cis-12 isomer of conjugated linoleic acid induces body composition changes in mice. Lipids $\mathbf{3 4}$, $235-241$

Payne RW, Lane PW and Genstat 5 Committee (1993) Genstat 5 Reference Manual. Oxford: Oxford Science Publications.
Pethick DW \& Dunshea FR (1993) Fat metabolism and turnover. In Aspects of Ruminant Digestion and Metabolism, pp. 291-311. [JM Forbes and J France, editors]. Wallingford, Oxon.: CAB International.

Ryder JW, Portocarrero CP, Song XM, Cui L, Yu M, Combatsiaris T, Galuska D, Bauman DE, Barbano DM, Charron MJ, Zierath JR \& Houseknecht KL (2001) Isomer-specific antidiabetic properties of conjugated linoleic acid. Improved glucose tolerance, skeletal muscle insulin action, and UCP-2 gene expression. Diabetes 50, 1149-1157.

Satory DL \& Smith SB (1999) Conjugated linoleic acid inhibits proliferation but stimulates lipid filling of murine 3T3-L1 preadipocytes. Journal of Nutrition 129, 92-97.

Sechen SJ, Dunshea FR \& Bauman DE (1990) Somatotropin in lactating cows: effect on response to adrenaline and insulin. American Journal of Physiology 258, E582-E588.

Stangl GI, Muller H \& Kirchgessner M (1999) Conjugated linoleic acid effects on circulating hormones, metabolites and lipoproteins, and its proportion in fasting serum and erythrocyte membranes of swine. European Journal of Nutrition 38, $271-277$

Tsuboyama-Kasaoka N, Takahashi M, Tanemura K, Kim HJ, Tange T, Okuyama H, Kasai M, Ikemoto S \& Ezaki O (2000) Conjugated linoleic acid supplementation reduces adipose tissue by apoptosis and develops lipodystrophy in mice. Diabetes 49, 1534-1542.

West DB, DeLany JP, Camet PM, Blohm F, Truett AA \& Scimeca J (1998) Effects of conjugated linoleic acid on body fat and energy metabolism in the mouse. American Journal of Physiology 275, R667-R672. 